\title{
The courage to learn
}

\author{
Ross M. Ungerleider, MD, MBA, ${ }^{\mathrm{a}}$ and Jamie Dickey Ungerleider, PhD, $\mathrm{MSW}^{\mathrm{b}}$
}

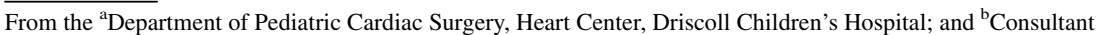
and Coach, Corpus Christi, Tex.

Disclosures: Authors have nothing to disclose with regard to commercial support.

Received for publication May 23, 2017; accepted for publication May 23, 2017; available ahead of print June 30, 2017.

Address for reprints: Ross M. Ungerleider, MD, MBA, Department of Pediatric Cardiac Surgery, Driscoll Children's Hospital, Furman Building, Corpus Christi, TX 78411 (E-mail: ungerlei@mac.com).

J Thorac Cardiovasc Surg 2017;154:1052-3

$0022-5223 / \$ 36.00$

Copyright (c) 2017 Published by Elsevier Inc. on behalf of The American Association for Thoracic Surgery http://dx.doi.org/10.1016/j.jtcvs.2017.05.086
}

\begin{abstract}
"All truth passes through 3 stages. First, it is ridiculed. Second, it is violently opposed. Third, it is accepted as being self-evident."

\section{-Arthur Schopenhauer}

Broberg and colleagues ${ }^{1}$ examine the human cost of innovation in our profession. That cost not only applies to patient lives lost in the quest to develop novel procedures, but also (not discussed by the authors) to the anguish of the dedicated health care professionals who understand that learning and growth require courage, struggle, and failure and who thereby become containers for the enormous grief, frustration, and occasionally disparagement that frequently accompanies those failures. The expedition to the arterial switch is landmarked with the names of those who have helped to distinguish our profession: Mustard, Senning, Quagebeur, Jatene, LeCompte, Ebert, Castaneda, and others. (It is meaningful that one of the authors of the article, Albert Starr, likely understands the consequences and challenges of innovation as much as any of us.) The authors emphasize that during the transition from the atrial to the arterial switch, mortality rates became the major factor for evaluating the merit of each procedure. As techniques developed and became more reproducible, particularly with coronary transfer, the mortality associated with the arterial switch began to decrease and ultimately enabled the procedure to reach the type of success expected in our current era: Mortality between $2 \%$ and $3 \%$ and anticipation of better long-term outcome (compared with patients with atrial switches) as they live beyond age 28 years.

In pediatric cardiac surgery today, the Society of Thoracic Surgeons Congenital Heart Surgery Database (STS-CHSD) tracks 1 single objective outcome parameter: Mortality. Compared with much of the other data reported by the STS-CHSD, mortality is a discrete, unarguable, and unambiguous metric. The intriguing question that is advanced by Broberg and colleagues ${ }^{1}$ is: If mortality rates were as visible during the era when the arterial switch was being developed, would our current fixation with STS-CHSD mortality rates as a reflector of institutional or individual excellence, our risk-aversion to becoming so-called outlier

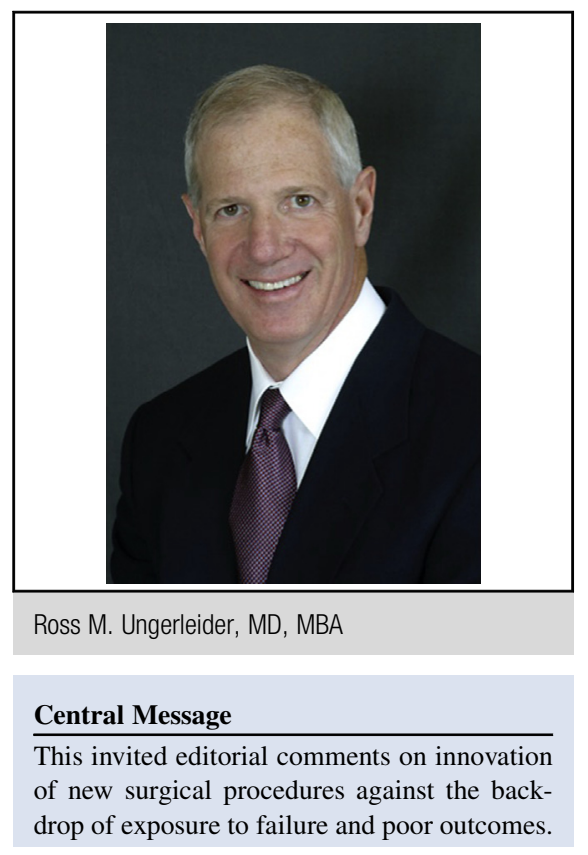

See Article page 1047.

centers, and the potential for legal or media exposure (or both), ${ }^{2}$ have been a strong deterrent to the development of what we now consider to be the surgical standard of care for infants with transposition of the great arteries?

In her landmark work on learning, Dweck ${ }^{3}$ provides a poignant and chilling description of the difference between fixed and growth mindsets. Quinn, ${ }^{4}$ in his extraordinary descriptions of creating transformational change, would label the difference between Dweck's 2 mindsets as "tellers" and "askers." We have referred to them as "knowers" and "learners." clear that our future depends on the courage of learners, askers, and those with growth mindsets to explore, innovate, and thoughtfully shine a light on the path that those stunted by already knowing would never traverse.

In our work with professionals over the past nearly 20 years, we have encountered the strong forces that prevent innovation: shame (of failure and/or being labeled a failure), need for perfection (and reflected validation), and discomfort with change. (We have so often heard the statement: "We've been doing it this way for years." Of course, we wonder if those same individuals are still listening to 8track tapes.) Try holding your hands in front of you, fingers interlaced. Notice the position of your thumbs. Now, switch the position of your thumbs, moving either the right or left thumb from on top of to below the other thumb. Notice the 
feeling of discomfort that this creates in your body. Many people very quickly revert to their more familiar position.

By writing this review, Boberg and colleagues ${ }^{1}$ invite us to reconnect to that courageous part within each of us ${ }^{9}$ that can switch the position of our metaphoric thumbs and live with the discomfort of change, particularly when there is exposure, albeit temporary, to struggle and failure. The authors stimulate us to channel our curiosity: What else can we improve? How can we do this thoughtfully, responsibly, and with permission to learn and transform?

\section{References}

1. Broberg CS, Shen I, Menashe V, Starr A. Emergence of the arterial switch procedure for transposition of the great arteries and the potential cost of surgical innovation. J Thorac Cardiovasc Surg. 2017;154:1047-51.

2. Dickey J, Damiano R, Ungerleider RM. Our surgical culture of blame: a time for change. J Thorac Cardiovasc Surg. 2003;126:1259-60.
3. Dweck CS. Mindset: the new psychology of success. New York: Bantam Books 2008.

4. Quinn RE. Deep change: discovering the leader within. San Francisco: JosseyBass; 1996.

5. Ungerleider JD, Ungerleider RM. Improved quality and outcomes through congruent leadership, teamwork and life choices. Prog Pediatr Cardiol. 2011; 32:75-83.

6. Ungerleider RM, Ungerleider JD. The seven practices of highly resonant teams. In: da Cruz M, Ivy D, Jaggers J, eds. Pediatric and congenital cardiology, cardiac surgery and intensive care. EVol. 6. London: Springer-Verlag; 2014:3423-50.

7. Ungerleider RM, Ungerleider JD, Ungerleider GD. Promoting occupation wellness and combating professional burnout in the surgical workforce. In: Sanchez JA, Barach P, Johnson JK, Jacobs JP, eds. Surgical Patient Care. Cham, Switzerland: Springer; 2017:205-25.

8. Ungerleider RM, Verghese GR, Ririe DG, Ungerleider JD. Selection, training, and mentoring of cardiac surgeons. In: Barach P, Jacobs JP, Lipshultz SE, Laussen PC eds. Pediatric and Congenital Cardiac Care. Vol 2. Heidelberg, Germany: Springer; 2015:9-39.

9. Ungerleider RM. Whom does the grail serve? Ann Thorac Surg. 2007;83: 1927-33. 